\title{
Moisture transfer in ready to eat multidomain foods (sweet and savoury snacking): an experimental and modelling study
}

\author{
C. Bourlieu ${ }^{1 *}$, E. Roca ${ }^{2}$, V. Guillard ${ }^{2}$, N. Gontard ${ }^{2}$, S. Guilbert ${ }^{1}$ \\ ${ }^{1}$ Joint Research Unit Agropolymers Engineering and Emerging Technologies, ENSAM-INRA, 2 pl. P. Viala, \\ 34060 Montpellier cedex 1, France; ${ }^{2}$ Joint Research Unit Agropolymers Engineering and Emerging \\ Technologies, University Montpellier II, cc023, pl. E. Bataillon, 34095 Montpellier cedex 5, France ;
}

\section{*claire.bourlieu@univ-montp2.fr}

Moisture migration between the distinct components of ready-to-eat multidomain food products affect the physical, specially texture, and chemical composition of the food system, and consequently, its quality and shelf-life (Katz and Labuza, 1981). This latter can be assessed by long experimental studies but also thanks to predictive models.

A global model based on a diffusive approach was developed to predict unidirectional water transfer into several multidomain foods products (Guillard et al., 2003; Guillard et al., 2004): it could be applied either in the case of direct or indirect contact between two components of distinct initial water activity (Table 1). This model, based on Fick's second law and the mass conservation equation, assumed instantaneous water activity equilibrium at the interface between components. It was successfully used to simulate moisture migration in numerous composite foods, presenting water activity gradients and compositions, representative of the sweet and savoury snack food range (Figure 1).

In this study, the model was validated using experimental moisture content profiles determined on a 30 days period in typical commercial multidomain food products: a sandwich, a bakery product and a mixed salad. These configurations were respectively represented by three food systems: \{a porous bakery / a wet protein-based food\}, \{a porous biscuit / a wet sweet-based food\}, \{a porous bakery / an agar gel $\}$. The model predictions were validated with moisture migration experimental studies which presented errors in the same range or lower than the model Root Mean Square Error of Prediction (Figure 2) .

This predictive tool will be of great interest to improve the quality of existing composite products but also to speed up the design of innovative food products with original organoleptic and nutritional properties.

Table 1. Hypothesis used for modelling moisture transfer in the 3 systems.

\begin{tabular}{|c|c|c|c|}
\hline & Model A & Model B & Model C \\
\hline $\begin{array}{l}\text { Application of } \\
\text { Fick's second } \\
\text { law }\end{array}$ & $\begin{array}{c}\forall i=[1 ; 2] \\
\frac{\partial \mathrm{X}_{\mathrm{i}}}{\partial \mathrm{t}}=\frac{\partial}{\partial \mathrm{x}}\left(\mathrm{D}_{\mathrm{i}} \frac{\partial \mathrm{X}_{\mathrm{i}}}{\partial \mathrm{x}}\right)\end{array}$ & $\begin{array}{c}\forall i=[1 ; 2 ; 3] \\
\frac{\partial \mathrm{X}_{\mathrm{i}}}{\partial \mathrm{t}}=\frac{\partial}{\partial \mathrm{x}}\left(\mathrm{D}_{\mathrm{i}} \frac{\partial \mathrm{X}_{\mathrm{i}}}{\partial \mathrm{x}}\right)\end{array}$ & $\begin{array}{c}\forall i=[1 ; 3] \\
\frac{\partial \mathrm{X}_{\mathrm{i}}}{\partial \mathrm{t}}=\frac{\partial}{\partial \mathrm{x}}\left(\mathrm{D}_{\mathrm{i}} \frac{\partial \mathrm{X}_{\mathrm{i}}}{\partial \mathrm{x}}\right)\end{array}$ \\
\hline $\begin{array}{c}\text { Initial } \\
\text { concentration }\end{array}$ & \multicolumn{3}{|c|}{ Uniform $\left(\mathrm{X}_{\mathrm{i}}\right)_{0}$ in each component $\mathrm{i}$} \\
\hline Interface & $a_{w 1}=a_{w 2}$ for $x=e_{1}$ & \multicolumn{2}{|c|}{$\begin{array}{l}\forall i=[1 ; 2] \text { for } x=\sum_{i} e_{i} \\
\qquad a_{w i}=\frac{H R v}{100} \\
v i+1\end{array}$} \\
\hline $\begin{array}{c}\text { Mass } \\
\text { conservation }\end{array}$ & $\begin{array}{c}\text { for } \mathrm{x}=\mathrm{e}_{1} \\
\mathrm{D}_{1} \rho_{\mathrm{ms} 1} \frac{\partial \mathrm{X}_{1}}{\partial \mathrm{x}}=\mathrm{D}_{2} \rho_{\mathrm{ms} 2} \frac{\partial \mathrm{X}_{2}}{\partial \mathrm{x}}\end{array}$ & $\begin{array}{c}\forall \mathrm{i}=[1 ; 2] \text { for } x=\sum_{i} e_{i} \\
\mathrm{D}_{\mathrm{i}} \rho_{\mathrm{msi}} \frac{\partial \mathrm{X}_{\mathrm{i}}}{\partial \mathrm{x}}=\mathrm{D}_{\mathrm{i}+1} \rho_{\mathrm{msi}+1} \frac{\partial \mathrm{X}_{\mathrm{i}+1}}{\partial \mathrm{x}}\end{array}$ & $\begin{array}{c}\forall i=[1 ; 3] \text { for } \mathrm{x}=\sum_{\mathrm{i}=1}^{\mathrm{i}=2} \mathrm{e}_{\mathrm{i}} \\
-\mathrm{D}_{\mathrm{i}} \rho_{\mathrm{msi}} \frac{\partial \mathrm{X}_{\mathrm{i}}}{\partial \mathrm{x}}=\frac{\mathrm{D}_{\mathrm{v}}}{\mathrm{e}_{\mathrm{v}}}\left(\mathrm{Cv}_{1}-\mathrm{Cv}_{2}\right)\end{array}$ \\
\hline $\begin{array}{l}\text { Moisture } \\
\text { concentration at } \\
\text { the extremities } \\
\text { of the system }\end{array}$ & $\begin{array}{c}x=0 \quad D_{1} \frac{\partial X_{1}}{\partial x_{1}}=0 \\
\mathrm{x}=\mathrm{e}_{1}+\mathrm{e}_{2} \quad \mathrm{D}_{2} \frac{\partial \mathrm{X}_{2}}{\partial \mathrm{x}_{2}}=0\end{array}$ & \multicolumn{2}{|c|}{$\begin{array}{c}x=0 \quad D_{1} \frac{\partial X_{1}}{\partial x_{1}}=0 \\
\text { for } \mathrm{x}=\mathrm{e}_{1}+\mathrm{e}_{2}+\mathrm{e}_{3} \quad \mathrm{D}_{3} \frac{\partial \mathrm{X}_{3}}{\partial \mathrm{x}_{3}}=0\end{array}$} \\
\hline
\end{tabular}




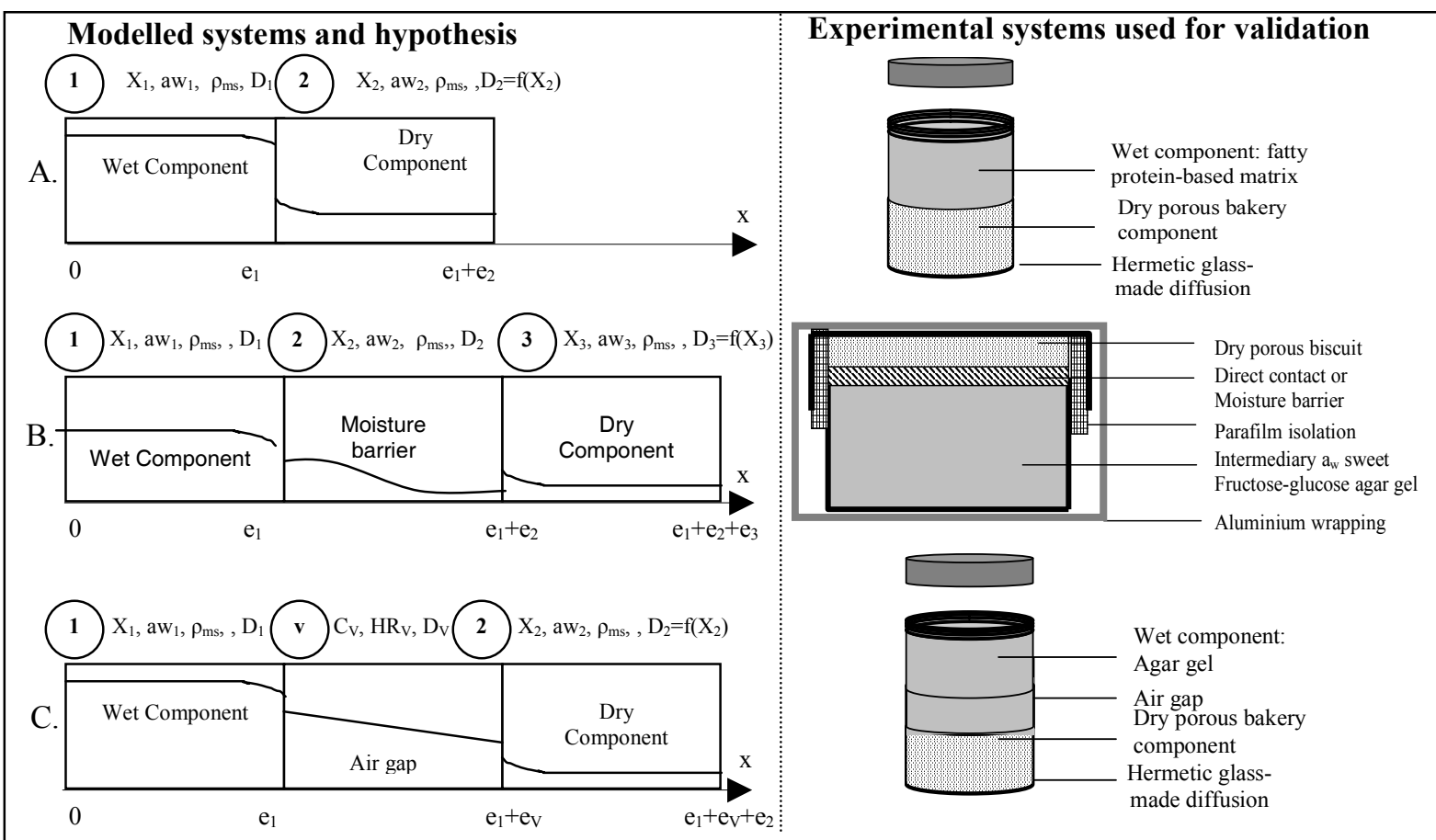

With $X_{i}$ water content, $e_{i}$ length, $a_{w i}$ water activity, $\rho_{m s i}$ apparent density, $D_{i}$ moisture effective diffusivity of component $i$; $C_{v}$ water vapour content, $e_{v}$ length, $H R_{v}$ Relative humidity, $D_{v}$ constant water vapour diffusivity $\left(2.6 \times 10^{-5} \mathrm{~m}^{2} / \mathrm{s}\right)$ of the internal air gap.

Figure 1. Schematic drawing of the modelled food components, their characteristics used as input data for modelling and corresponding experimental systems used to validate predictions.

A.

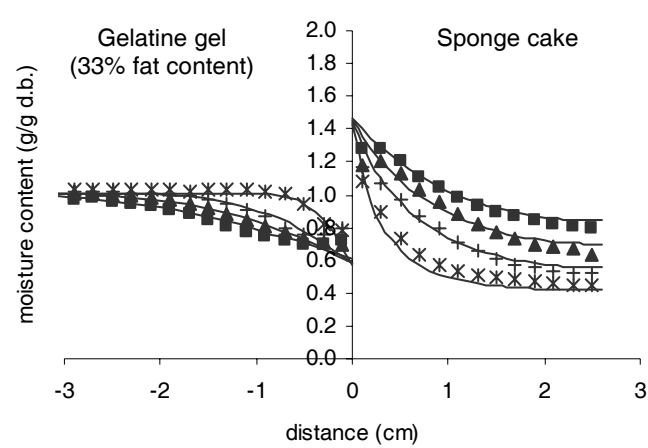

B.

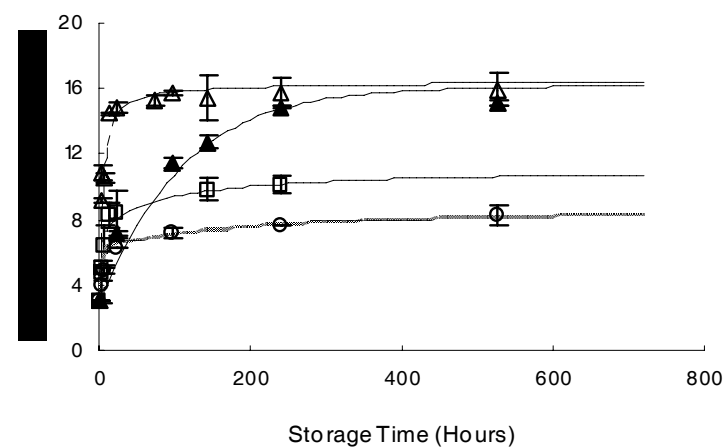

C.

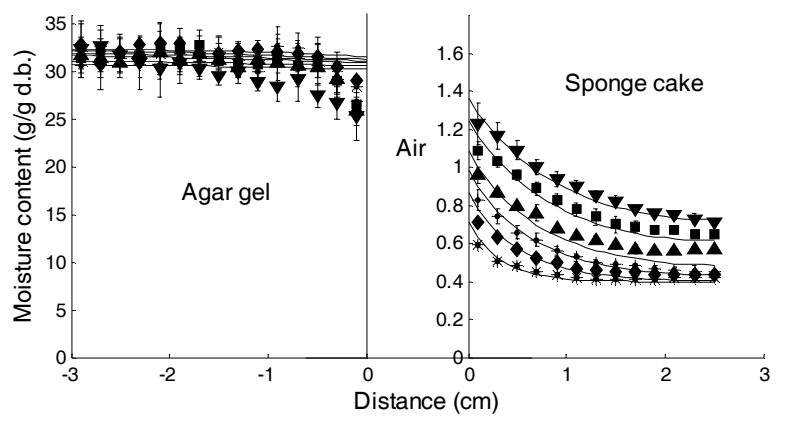

Fig.2. A) Moisture contents profiles in a fatty gelatine gel in contact with a porous wet bakery after $1(*), 6$ $(+), 10(\mathbf{\Delta})$ and $20(\mathbf{\square})$ days of storage at $\left.20^{\circ} \mathrm{C} ; \mathrm{B}\right)$ Global moisture content in a porous dry bakery product in direct contact with a $0.75 \mathrm{a}_{\mathrm{w}}$ gel $(\Delta)$, a 0.60 $\mathrm{a}_{\mathrm{w}}$ gel $(\square)$, a $0.5 \mathrm{a}_{\mathrm{w}}$ gel $(O)$ and in contact with a 0.75 $\mathrm{a}_{\mathrm{w}}$ gel with a $300 \mu \mathrm{m}$ dark chocolate barrier at the interface ( $\mathbf{\Delta})$; C) Moisture content profiles in an agar gel and a porous wet bakery separated by a gaseous phase of $1 \mathrm{~cm}$ length after $1(*), 3(\bullet), 6(+), 10(\mathbf{\Delta})$, $20(\mathbf{\square})$ and $30(\boldsymbol{\nabla})$ days of storage at $20^{\circ} \mathrm{C}$

Predicted (lines) and experimental data (symbols).

\section{References}

Guillard, V., Broyart, B., Bonazzi, C., Guilbert, S., Gontard, N., 2003. Evolution of moisture distribution during storage in a composite food. Modeling and simulation. Journal of Food Science 68, 958-966.

Guillard, V., Broyart, B., Guilbert, S., Bonazzi, C., Gontard, N., 2004. Moisture diffusivity and transfer modelling in a dry biscuit. Journal of Food Engineering 64, 81-87.

Katz, E. E., Labuza, T. P., 1981. Effect of Water Activity on the Sensory Crispness and Mechanical Deformation of Snack Food-Products. Journal of Food Science 46, 403-409. 